\title{
Intubating conditions, onset, duration and side effects with rocuronium and atracurium: A comparative study
}

\author{
Naik R. ${ }^{1}$, Thakur R. ${ }^{2}$, Sahare K.K. ${ }^{3}$, Lakra A.M. ${ }^{4}$, Singh D. ${ }^{5}$, Bhagat C.P. ${ }^{6}$ \\ ${ }^{1}$ Dr. Rashmi Naik, Associate Professor, ${ }^{2}$ Dr. Rashmi Thakur, Associate Professor, ${ }^{3}$ Dr. K.K. Sahare, Professor, ${ }^{4}$ Dr. A.M. \\ Lakra, Professor, ${ }^{5}$ Dr. Deepak Singh, Associate Professor, ${ }^{6}$ Dr. C.P. Bhagat, Assistant Professor; all authors are attached \\ with Department of Anesthesiology and Critical Care, Pt. J. N. M. Medical College, Raipur, Chhattisgarh, India.
}

Corresponding Author- Dr. Rashmi Thakur, Associate Professor, Department of Anesthesiology and Critical Care, Pt. J. N. M. Medical College, Raipur, Chhattisgarh, India. E-mail: rash15nov@gmail.com

\begin{abstract}
Objective(s): To compare the intubating conditions, onset and duration of action, side effects and complications with rocuronium bromide and atracurium besylate. Material and Method: This prospective, randomized double blind study was conducted with a sample size of 100 patients. After standard general anaesthesia technique group I received IV. rocuronium bromide $0.6 \mathrm{mg} / \mathrm{kg}$ and group II received iv. atracurium besylate $0.5 \mathrm{mg} / \mathrm{kg}$. Laryngoscopy was attempted60 sec after administration of NMBA and thereafter every $30 \mathrm{sec}$ till good or excellent intubating conditions were achieved. Intubating condition was scored on fourpoint scale (0-3). Intubating conditions, onset and duration, side effects and complications were observed and recorded. Result: Overall intubating condition was acceptable (excellent + good) in $50(100 \%)$ patients in group I and 47(94\%) patients in group II. It was excellent in $45(90 \%)$ and $16(32 \%)$ patients in group I and II respectively. Good intubating condition was found in 5(10\%) and 31(62\%) patients in group I and II respectively. Fair intubating condition was found in $3(6 \%)$ patients in group II. None of the patients had poor intubating condition in either group. Cutaneous flushing was found in $4 \%$ cases in group II. No other side effects and complications were observed. Conclusion: Rocuronium with its faster initial response and possibly early laryngeal muscle paralysis provides better intubating conditions in shorter duration of time than atracurium.
\end{abstract}

Key words: Rocuronium, Atracurium, Intubating condition, Neuromuscular blocking agent.

\section{Introduction}

The ease of intubation depends on the degree of muscle relaxation, depth of anaesthesia and skill of anaesthesiologist. For successful, easy and atraumatic intubation, muscle paralysis of quick onset is desirable. Neuromuscular blocking agents (NMBA) during general anaesthesia, facilitates endotracheal intubation and also provides surgical relaxation.

The onset time, duration of a muscle relaxation and type of surgery are critical factors in choosing the appropriate NMBA to achieve rapid successful tracheal intubation [1]. In describing the characteristics of an ideal neuromuscular blocking agent Savarese and Kitz in 1973 pointed out the importance of a fast onset of action, a short duration, cardiovascular stability, lack of accumulation and easy reversibility. Other desirable features of the ideal neuro muscular blocking agent are

Manuscript received: $14^{\text {th }}$ November 2018

Reviewed: $24^{\text {th }}$ November 2018

Author Corrected: $30^{\text {th }}$ November 2018

Accepted for Publication: $4^{\text {th }}$ December 2018 the absence of histamine liberation, no significant drug interactions, no increased effect on intraocular or intracranial pressures and the absence of metabolites and significant pharmacological effect [2]. Rocuronium bromide is an aminosteroidalnon-depolarizing neuromuscular blocking agent. This desacetoxy derivative of vecuronium almost fulfils the criteria of an ideal neuromuscular blocking agent.

It has rapid onset and intermediate duration of action, minimum cardiovascular side effects, no histamine release and no active metabolites [3,4]. Atracurium besylate is another intermediate acting, non depolarizing neuromuscular blocking agent. It has the unique property of metabolism by a non-enzymatic pathway, the Hoffmann degradation. Thus, it can be given safely in renal and hepatic diseases [5]. The present study is aimed to compare the intubating conditions, onset and duration of action, side effects and complications with rocuronium and atracurium. 


\section{Material and Method}

After obtaining institutional scientific and ethics committee approval the study was carried out in the Department of Anesthesiology and Critical Care, Pt J. N. M. Medical College, Raipur, Chhattisgarh.

Inclusion criteria- It was a prospective, randomized, double blind study where 100 patients of either sex, aged 20-60 year, ASA grade I and II of Mallampati grade 1 and 2 undergoing elective surgery under general anaesthesia were included.

Exclusion criteria- Patients refused to enroll in the study or with anticipated difficult airway, neuromuscular disorder, allergy to any medication, pregnancy, patients on aminoglycoside antibiotic; hepatic, renal and cardiovascular disease, electrolyte and acid base imbalance were excluded from the study.

Preoperative assessment was done day before surgery and relevant investigations were checked. On the day of surgery history, findings and investigations were reviewed. Written informed consent was obtained from all the patients and were randomly divided into 2 groups by sealed envelope technique. Patients of group I ( $\mathrm{n}=50$ ) received IV rocuronium bromide $0.6 \mathrm{mg} / \mathrm{kg}$ for intubation and supplemental dose of $0.15 \mathrm{mg} / \mathrm{kg}$. [6] While the patients of group II ( $\mathrm{n}=50$ ) received iv atracurium besylate $0.5 \mathrm{mg} / \mathrm{kg}$ for intubation and supplemental dose of $0.1 \mathrm{mg} / \mathrm{kg}$. [7] Premedication was done with iv glycopyrrolate $0.2 \mathrm{mg}$, iv pentazocine $0.6 \mathrm{mg} / \mathrm{kg}$ and iv midazolam $0.4 \mathrm{mg} / \mathrm{kg} 30 \mathrm{~min}$ prior to surgery in the preoperative room.

On receiving the patient in the operation theatre monitors were connected. Vital parameters were checked and baseline values were recorded. An intravenous line was established using an 18 gauge IVcanula and crystalloid infusion was started. Patients were preoxygenated with $100 \%$ oxygen for $5 \mathrm{~min}$, using Magill's circuit with face mask. Induction was done with iv thiopentone sodium 4-6 mg/kg predetermined dose of either rocuronium bromide or atracurium besylate was given. Intermittent positive pressure ventilation was done. Laryngoscopy was attempted at $60 \mathrm{sec}$ after administration of NMBA and thereafter every $30 \mathrm{sec}$ till good or excellent intubating conditions were achieved. Intubating condition was scored on four point scale (0-3) described by Cooper et al [4].

\begin{tabular}{|c|c|c|c|}
\hline Score & Jaw Relaxation & VocalCords & Response to Intubation \\
\hline 0 & Poor (Impossible) & Closed & Severe Coughing/Bucking \\
\hline 1 & Minimal (Difficult) & Closing & Mild Coughing \\
\hline 2 & Moderate (Fair) & Moving & Slight Diaphragmatic Movement \\
\hline 3 & Good & Open & None \\
\hline
\end{tabular}

Score from each group was added together to give overall intubation score: excellent (8-9), good (6-7), fair (3-5) and poor $(0-2)$.

Anaesthesia was maintained with $\mathrm{O}_{2}: \mathrm{N}_{2} \mathrm{O}(40: 60)$, halothane $0.5-1 \%$ and iv rocuronium bromide or atracurium besylate using Bain's circuit and controlled ventilation. For neuromuscular monitoring, the electrodes were placed on the ulnar side of the volar aspect of wrist, so as to stimulate the ulnar nerve. Visual estimation of baseline TOF was done after induction and before NMBA and 4 equal twitches were noted.TOF was applied at every $12 \mathrm{sec}$ interval for initial $3 \mathrm{~min}$ after administration of NMBA and then every 5 min interval throughout the surgery. Onset time is defined as the time from end of injection of neuromuscular blocking agent to the complete ablation of $\mathrm{T}_{1}$ of TOF and clinical duration as the time from end of injection of neuromuscular blocking drug until recovery of $\mathrm{T}_{1}$ of TOF. NMBA was supplemented when three twitches of TOF was seen.

Vital parameters were recorded at regular interval till the end of surgery. At the end of surgical procedure $\mathrm{N}_{2} \mathrm{O}$ and halothane were stopped and 100\% oxygen was given. The reversal of neuromuscular blocking agent was done with IV glycopyrrolate $0.01 \mathrm{mg} / \mathrm{kg}$ and iv neostigmine $0.05 \mathrm{mg} / \mathrm{kg}$ after return of spontaneous respiration and when TOF showed $25 \%$ recovery. Patients were extubated after oropharyngeal suction and then $100 \% \mathrm{O}_{2}$ was given with the face mask for 5 min. Assessment of recovery was done using the clinical parameters such as eye opening, response to verbal command, head raising, hand grip and confirmed by NMM. Patients were then shifted to recovery room for further observation. 


\section{Original Research Article}

Sample size- For the purpose of power analysis, we used the study of Whalley D.G. et al. (8) They found that mean onset time in rocuronium group was 59.0+/- 22.2 seconds and onset time in atracurium group was $98.6+/-41.4$ seconds. Taking this into consideration, we calculated the difference between these two mean with confidence level $95 \%$, $\alpha$ err probability $0.05 \%$ in $90 \%$ power, minimum 39 samples are required as calculated by Epitools Software. So we decided to include 100 patients $(\mathrm{n}=50)$.

Statistical analysis- All the data were calculated with the help of graph-pad in stat software for statistical analysis. The Categorical variables were presented as numbers (percent). The quantitative data are being represented as Mean and standard deviation and were compared between groups using Student $t$-test. $P$ value less than 0.05 was considered as significant and $P$ value less than 0.001 was taken as statistically highly significant.

\section{Result}

Table-1: Demographic profile.

\begin{tabular}{|c|c|c|c|}
\hline Parameter & Group I & Group II & p value \\
\hline Age (yr) & $34.06 \pm 10.79$ & $34.90 \pm 10.78$ & 0.9889 \\
\hline Weight (kg) & $47.78 \pm 6.40$ & $48.80 \pm 6.93$ & 0.4464 \\
\hline Sex (M:F) & $23: 27$ & $24: 26$ & \\
\hline
\end{tabular}

Demographic profile like mean age, mean weight and sex ratio were comparable between both the groups.

Table-2: Intubating conditions.

\begin{tabular}{|c|c|c|c|c|c|c|}
\hline \multirow{2}{*}{ Score } & \multicolumn{2}{|c|}{ Jaw Relaxation } & \multicolumn{2}{c|}{ Vocal Cords } & \multicolumn{2}{c|}{ Response to Intubation } \\
\cline { 2 - 7 } & $\begin{array}{c}\text { Group I } \\
\text { No. (\%) }\end{array}$ & $\begin{array}{c}\text { Group II } \\
\text { No. (\%) }\end{array}$ & $\begin{array}{c}\text { Group I } \\
\text { No. }(\%)\end{array}$ & $\begin{array}{c}\text { Group II } \\
\text { No. }(\%)\end{array}$ & $\begin{array}{c}\text { Group I } \\
\text { No. }(\%)\end{array}$ & $\begin{array}{c}\text { Group II } \\
\text { No. (\%) }\end{array}$ \\
\hline 0 & 0 & 0 & 0 & 0 & 0 & 0 \\
\hline 1 & 0 & 0 & 0 & $2(4)$ & 0 & $10(20)$ \\
\hline 2 & $5(10)$ & $15(30)$ & $15(30)$ & $38(76)$ & $5(10)$ & $15(30)$ \\
\hline 3 & $45(90)$ & $35(70)$ & $35(70)$ & $10(20)$ & $45(90)$ & $25(50)$ \\
\hline
\end{tabular}

Table-3: Overall intubation score.

\begin{tabular}{|c|c|c|}
\hline Intubating Conditions & $\begin{array}{c}\text { Group I } \\
\text { No. }(\%)\end{array}$ & $\begin{array}{c}\text { Group II } \\
\text { No. }(\mathbf{\%})\end{array}$ \\
\hline Poor (0-2) & 0 & 0 \\
\hline Fair (3-5) & 0 & $3(6)$ \\
\hline Good (6-7) & $5(10)$ & $31(62)$ \\
\hline Excellent (8-9) & $45(90)$ & $16(32)$ \\
\hline
\end{tabular}

Overall intubating condition was acceptable (excellent + good) in 50(100\%) patients in group I and 47(94\%) patients in group II. It was excellent in 45(90\%) and 16(32\%) patients in group I and II respectively. Good intubating condition was found in $5(10 \%)$ and $31(62 \%)$ patients in group I and II respectively. Fair intubating condition was found in $3(6 \%)$ patients in group II. None of the patients had poor intubating condition in either group.

Table-4: Onset and duration of action.

\begin{tabular}{|c|c|c|}
\hline Group & $\begin{array}{c}\text { Onset }(\mathbf{s e c}) \\
\text { Mean } \pm \text { SD }\end{array}$ & $\begin{array}{c}\text { Duration (min) } \\
\text { Mean } \pm \text { SD }\end{array}$ \\
\hline I & $85.36 \pm 4.89$ & $28.98 \pm 3.93$ \\
\hline II & $112.46 \pm 13.56$ & $30.84 \pm 4.54$ \\
\hline p value & $<0.0001$ & 0.0309 \\
\hline
\end{tabular}

Onset was significantly faster in rocuronium group than atracurium group. Duration of action was also significantly short in rocuronium group. 
Original Research Article

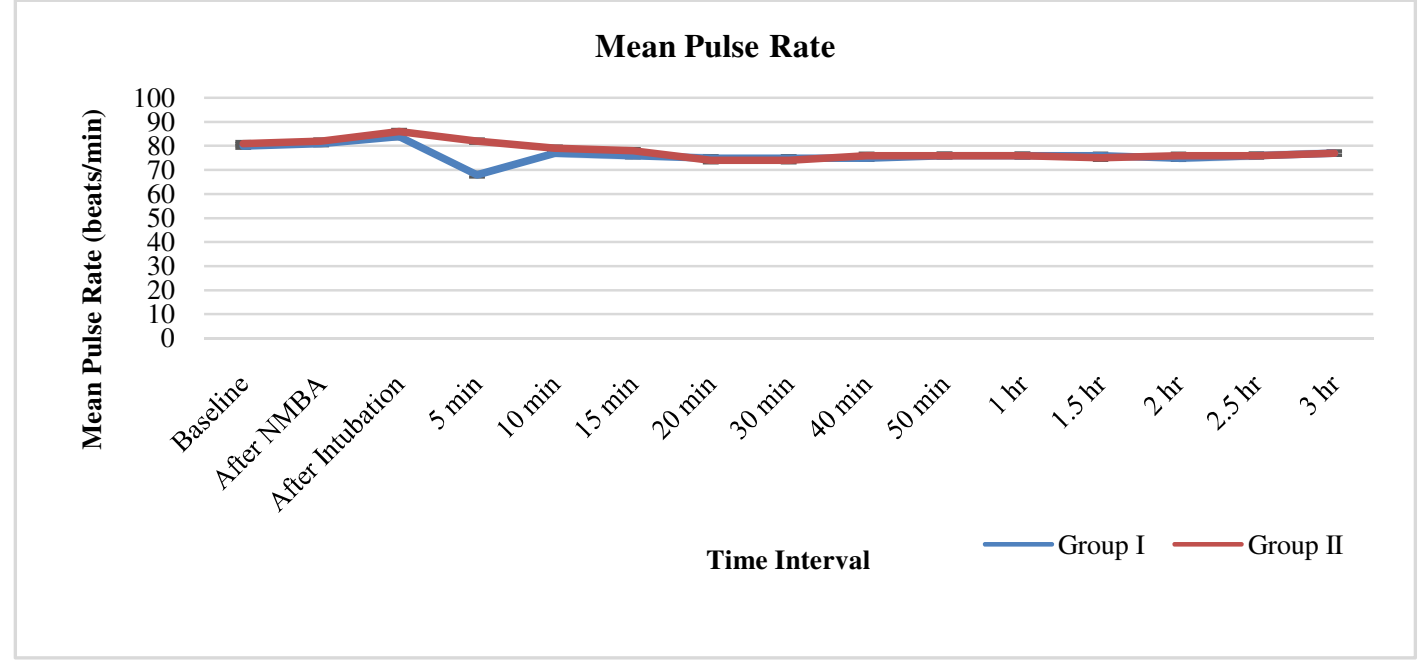

\section{Graph-1: Mean pulse rate}

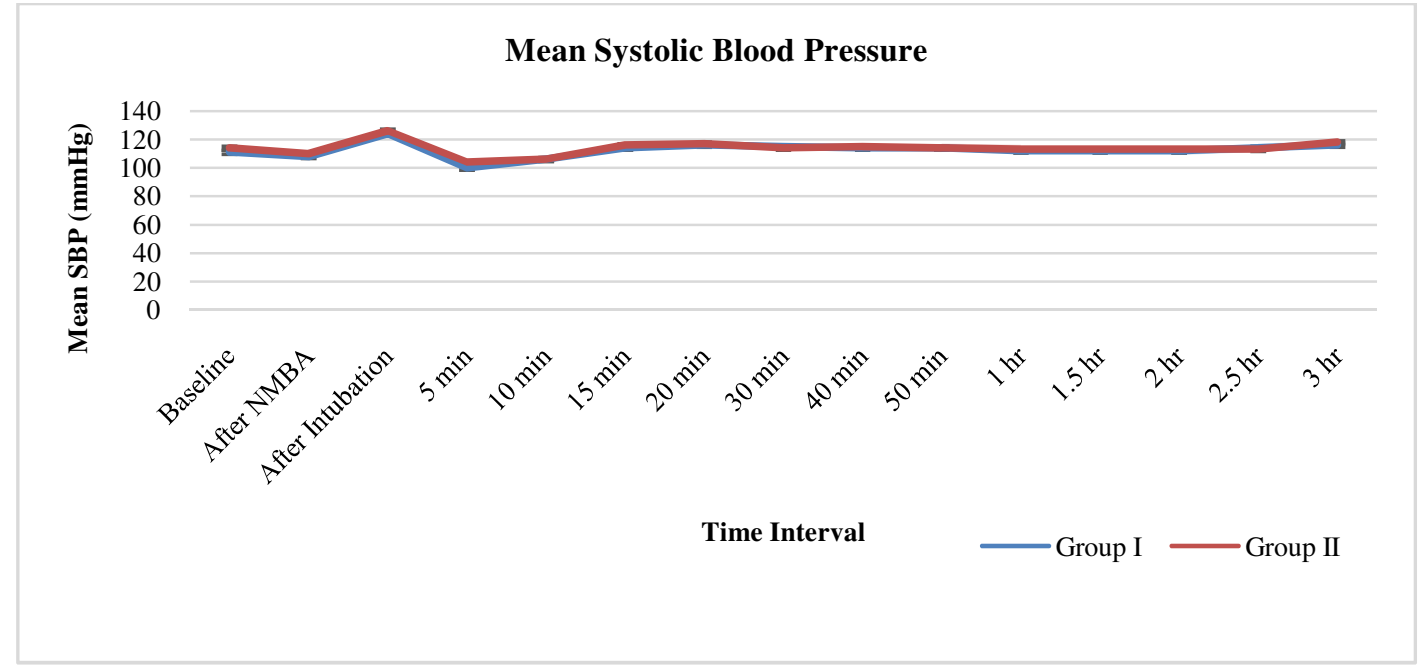

Graph-2: Mean systolic blood pressure

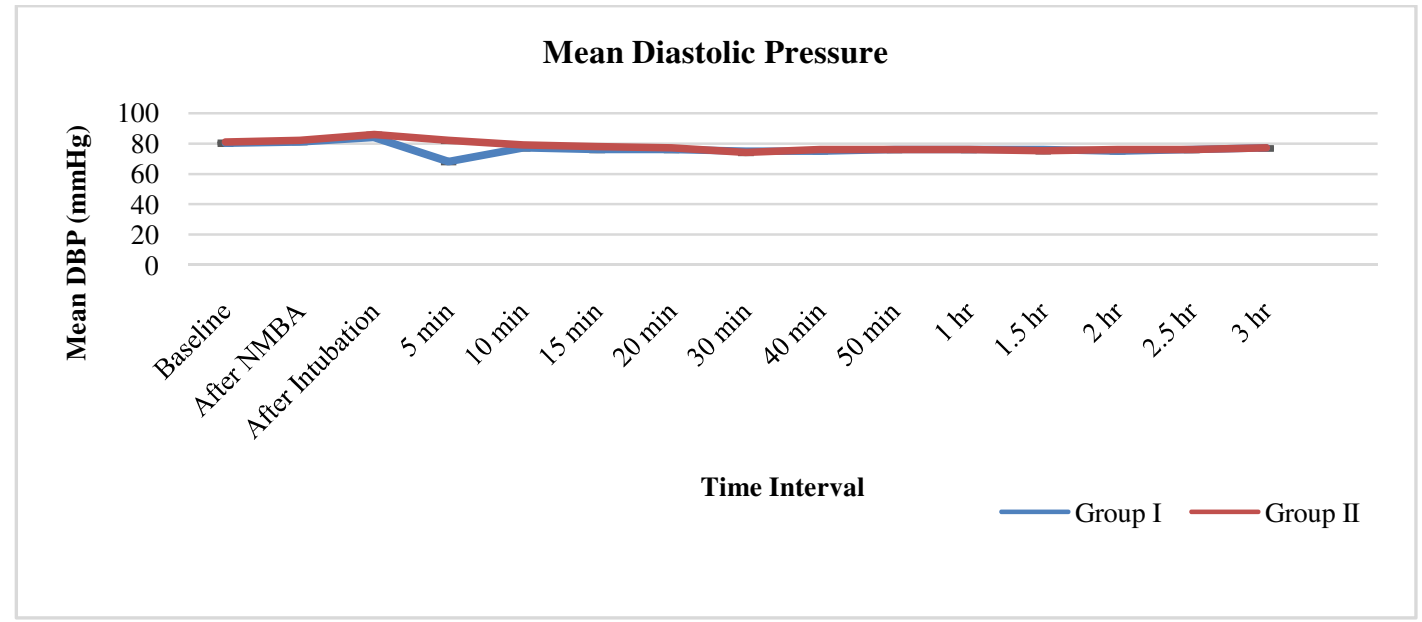

Graph-3: Mean diastolic blood pressure

Haemodynamic parameters (HR, SBP, DBP) measured at various time interval were comparable in both the groups at all time intervals. Significant rise in PR, SBP and DBP from baseline was observed following intubation in both the groups. This was consistent with the stress response to laryngoscopy and intubation which came nearly to baseline within 10 minutes. 
Table-5: Side effects.

\begin{tabular}{|c|c|c|}
\hline Side Effects & $\begin{array}{c}\text { Group I } \\
\text { No. }(\text { \%) }\end{array}$ & $\begin{array}{c}\text { Group II } \\
\text { No. }(\%)\end{array}$ \\
\hline Cutaneous Flushing & 0 & $2(4)$ \\
\hline Hypotension & 0 & 0 \\
\hline Bronchospasm & 0 & 0 \\
\hline Others & 0 & 0 \\
\hline
\end{tabular}

Only two patients had cutaneous flushing in atracurium group. There were no other complications observed in either group.

\section{Discussion}

Provision of muscle relaxation for endotracheal intubation demands the neuromuscular blocking agent that provides good intubating conditions in short time, with stable haemodynamic profile and minimum side effects. Rocuronium is a non-depolarizing agent having low potency with relatively shorter onset of action and intermediate duration. Lack of cardiovascular response of rocuronium is due to markedly less vagolytic property, absent ganglion blocking and histamine releasing effect.

Atracurium is another intermediate acting neuromuscular blocking agent, which can be given safely in hepatic and renal disease. On the other hand, atracurium has potential to release histamine. Ideal intubating condition depends on factors like degree of muscle relaxation, depth of anaesthesia and skill. Overall intubating condition was acceptable (excellent + good) in 50(100\%) patients in group I and $47(94 \%)$ patients in group II. It was excellent in $45(90 \%)$ and $16(32 \%)$ patients in group I and II respectively. Good intubating condition was found in $5(10 \%)$ and $31(62 \%)$ patients in group I and II respectively. Fair intubating condition was found in $3(6 \%)$ patients in group II.

None of the patients had poor intubating condition in either group. Mirakhur et al also found acceptable intubating conditions in $90 \%$ case with atracurium 0.5 $\mathrm{mg} / \mathrm{kg}$, under halothane/fentanyl anaesthesia [9]. Cooper $\mathrm{R}$ et al reported acceptable intubating conditions in $100 \%$ cases with rocuronium $0.6 \mathrm{mg} / \mathrm{kg}$, with alfentanil and thiopentone [4]. Burder Fuchs $\mathrm{T}$ et al found acceptable intubating conditions in $100 \%$ cases with rocuronium $0.6 \mathrm{mg} / \mathrm{kg}$, with alfentanil and thiopentone [1]. Excellent intubating conditions were reported in $94 \%$ and good in $6 \%$ cases. Bunburaphong $\mathrm{P}$ et al found acceptable intubating condition in $95 \%$ and excellent in $30 \%$ patients with rocuronium $0.5 \mathrm{mg} / \mathrm{kg}$. [10]. Thus the intubating conditions were comparable with our study. At complete ablation of $\mathrm{T}_{1}$ of TOF, it was fairly easy to intubate the patient and this could be due tomore rapid onset at adductor muscles of larynx. The proximity of adductor muscles of larynx to the aorta, the resultant higher blood supply, and rapid access of NMBA to the neuromuscular junction of laryngeal muscles has been thought as the reason for rapid action of rocuronium [11]. Time of onset in our study was $85.36 \pm 4.89 \mathrm{sec}$ and $112.46 \pm 13.56 \mathrm{sec}$ with group I and II respectively using TOF stimulation of ulnar nerve at wrist.

This difference was statistically significant $(\mathrm{p}=0.0001)$. Purhinger et alreported the onset of action of rocuronium was $91 \pm 28 \mathrm{sec}$ with propofol and fentanyl. Single twitch was used for Neuromuscular monitoring [12]. Whalley et al reported onset of action of atracurium $0.5 \mathrm{mg} / \mathrm{kg}$ to be $98.6 \pm 41.4 \mathrm{sec}$ with propofol/ alfentanil with $\mathrm{N}_{2} \mathrm{O}$ and $\mathrm{O}_{2}$. TOF was used for NMM [8]. Saxen are ported onset time of rocuronium $0.6 \mathrm{mg} / \mathrm{kg}$ was78.3 $\pm 1.8 \mathrm{sec}$ who used single twitch for NMM [13]. Elbradie Samia reported onset of action of atracurium $0.5 \mathrm{mg} / \mathrm{kg}$ was $94 \pm 26 \mathrm{sec}$ after induction was with propofol and fentanyl. TOF was used for NMM[7].

It was comparable to our study. Singh Ajit et alreported onset of rocuronium to be $87.94 \mathrm{sec}(71-90 \mathrm{sec})$. Single twitch was used for NMM [14]. Our study was within the range, minor variation may be due to monitoring technique. Onset time of neuromuscular block depend on type of drug, dose and methods of assessing neuromuscular block. In our study we used rocuroniuma steroidal compound and atracurium- a benzylisoquinolinium compound in a dose of 2 x ED 95 dose-0.6 $\mathrm{mg} / \mathrm{kg}$ and $0.5 \mathrm{mg} / \mathrm{kg}$ for intubation. Rocuronium shows faster onset of action than the atracurium. The reason being, suggested the low potency of rocuronium, entailing the presence of more relaxant molecules in blood stream resulting in large concentration gradient towards the biophase. According to a study done by 


\section{Original Research Article}

Meistelman $\mathrm{C}$ et al orbicularis oculi exhibits similar features i.e. time course of neuromuscular blockade and sensitivity to muscle relaxants to that of laryngeal adductors and the diaphragm which are blocked more rapidly than the peripheral adductor muscles of thumb[15]. The faster onset of neuromuscular blockade at Orbicularis oculi compared to Adductor Pollicis might be due to differences in circulation time and muscle blood flow. Muscles which are closer to the central circulation like the orbicularis occuli or the diaphragm have relatively greater perfusion and tend to be paralysed more rapidly than the more peripheral muscles like adductor pollicis.

Orbicularis oculi is made up of small, round and 89\% fast twitch type II fibres. Adductor pollicis is made up of slow oxidative type of fibres. Onset time differs with different nerve stimulation techniques (single twitch, TOF etc) and rates used. Duration of action was $28.98 \pm 3.93 \mathrm{~min}$ and $30.84 \pm 4.54 \mathrm{~min}$ with rocuronium and atracurium respectively. This difference was statistically not significant. Khuenl-Brady K.S. et al reported duration of action of rocuronium was $28 \mathrm{~min}$. [16]. Sehgal Arun et al reported duration of action of rocuronium 25.36 $\pm 5.87 \mathrm{~min}$. [17] Singh Ajit et alfound duration of action of rocuronium $27.4 \mathrm{~min}$. [14].

The study conducted byKhuenl-Brady K.S. et al, Sehgal Arun et al, and Singh Ajit et al are comparable to our study, may be due to similar background anaesthesia $\left(\mathrm{O} 2+\mathrm{N}_{2} \mathrm{O}+\right.$ halothane based $)$ and comparable demographic profile. Awasthi et alreported duration of atracurium 32.9 min. [18]. Bharti Neeraja et al found duration of atracurium $32.05 \mathrm{~min}$ which was comparable to our study[19]. In our study cutaneous flushing was seen in $2(4 \%)$ patients in atracurium group. None of the patients in either group has any other side effect.

Mirakhur et alreported cutaneous flushing in $18 \%$ patients with atracurium $0.4 \mathrm{mg} / \mathrm{kg}$ and $73 \%$ with 1 $\mathrm{mg} / \mathrm{kg}$. $\quad 0.5 \%$ cases had brochospasm [9] Wierda J.M.K.H. et al reported no side effects with rocuronium $0.6 \mathrm{mg} / \mathrm{kg}$. [20] Bunburaphong P. et alstudied intubating conditions with three different doses of rocuronium.

No serious side effects or complications were observed [10]. Elbradie S. reported clinical signs of histamine release in $62 \pm 10 \%$ patients with atracurium $0.5 \mathrm{mg} / \mathrm{kg}$, which was not reported with rocuronium [7]. Increased incidence of side effects reported by Elbradie S. may be due to atopic individual or rapid administration of atracurium. Atracurium has tendency to release histamine when higher dose is used and administered rapidly, characterized by cutaneous manifestation, bronchospasm, hypotension and tachycardia. There were few studies available on comparison between atracurium and rocuronium. All the previous studies were done using smaller sample size so we decided to do this study with larger sample size.

\section{Conclusion}

Rocuronium with its faster initial response and possibly early laryngeal muscle paralysis provides better intubating conditions in short time than atracurium. Thus rocuronium can be a choice for intubation where depolarizing NMBA are contraindicated. Hemodynamic parameters are similar in both the groups.

\section{Funding: Nil, Conflict of interest: None Permission of IRB: Yes}

\section{References}

1. Fuchs-Buder T. and Tassonyi E. Intubating conditions and time course of rocuronium-induced neuromuscular block in children. $\mathrm{Br} \mathrm{J}$ Anaesth. 1996; 77:335-38.

2. Savarese JJ. and Kitz RJ. Does clinical anesthesia need new neuromuscular blocking agents? Anesthesiology 1975;42 (3):236-39.

3. Stoelting R.K. Neuromuscular blocking drugs pharmacology and physiology in Anaesthetic practice. Lippincott Raven USA $3^{\text {rd }}$ Edition, 1999; 182-23.

4. Cooper R., Mirakhur R. K., Clarke R. S. J.and Boules Z. Comparison of intubating conditions after administration of ORG 9426 (rocuronuium) and suxamethonium. Br. J. Anaesth. 1992;69:269-73.

5. Payne JP, Hughes R. Evaluation of atracurium in anaesthetized man. Br J Anaesth. 1981 Jan;53(1): 45-54.

6. Darshna D Patel and Varsha N Swadia. Rocuronium bromide versus vecuronium bromide: Comparison of onset, intubatimg condition and duration of action. Int J Res Med. 2013;2(2):137-41.

7. Elbradie Samia. Neuromuscular efficacy and histamine release hemodynamic changes produced by rocuronium vs atracurium: A comparative study. Journal of Egyptian Nat. cancer Inst. 2004; 16: 107-13. 
8. Whalley DG, Maurer WG, Knapik AL, et al. Comparison of neuromuscular effects, efficacy and safety of rocuronium and atracurium in ambulatory anaesthesia. Can J Anaesth. 1998 Oct;45(10):954-9. DOI:10.1007/BF03012303.

9. Mirakhur RK, Lavery GG, Clarke RS, et al. Atracurium in clinical anaesthesia: effect of dosage on onset, duration and conditions for tracheal intubation. Anaesthesia. 1985 Aug;40(8):801-5.

10. Bunburaphong P., Werawataganon $\mathrm{T}$ and Panyarachun K. Intubating conditions after three different doses of rocuronium in elderly. Can $\mathrm{J}$. Anaesth. 1998; 45(10): 954-9.

11. Plaud B, Proost JH, Wierda JM, et al. Pharmacokinetics and pharmacodynamics of rocuronium at the vocal cords and the adductor pollicis in humans. Clin Pharmacol Ther. 1995 Aug;58 (2):185-91. DOI: 10.1016/0009-9236 (95) 90196-5.

12. Pühringer FK, Sparr HJ, Mitterschiffthaler G, et al. Extended duration of action of rocuronium in postpartum patients. Anesth Analg. 1997 Feb; 84(2): 352-4.

13. Saxena, A.H. Rocuronium bromide: a clinical trial. J. Anaesth. Clin. Pharmacol. 1999 Apr.; 15 (2): 183-85.

14. Singh Ajeet and Bhatia Pradeep Kumar. Comparision of onset time, duration of action and intubating conditions with suxamethonium and rocuronium. Indian. J. Anaesth.2004;48(2):129-33.

15. Meistelman Claude, Plaude B. and Donati F. Rocuronium (ORG 9426) neuromuscular blockade at the adductor muscles of larynx and adductor pollicis in humans. Can I. Anaesth.1992 Sep; 39 (7): 665-69.

16. Khuenl-Brady KS, Pomaroli A, Pühringer F, et al. The use of rocuronium (ORG 9426) in patients with chronic renal failure. Anaesthesia. 1993 Oct;48(10): 873-5.

17. Sehgal Arun, Sharma R.K. and Kumar Indrani. Comparison of intubating conditions and time course action of Rocuronium Bromide and Vecuronium Bromide. Ind. J. Anaesth. 2001;45 (4): 255-58.

18. Awasthi S.N., Swe K.K. and Kyi D.W. Initial clinical experience with atracurium. Ind $\mathrm{J}$. Anaesth.1987;35(2):128-32.

19. Bharti Neeraja, Sharma Sunil, Goel S.K. and Deepak Falgune. Rocuronium: Time course of action and intubation conditions,- A comparison with atracurium and vecuronium. Indian J. Anaesth. 2001; 45 (5):363.

20. Wierda JM, de Wit AP, Kuizenga K, et al. Clinical observations on the neuromuscular blocking action of Org 9426, a new steroidal non-depolarizing agent. Br J Anaesth. 1990 Apr;64(4):521-3.

\section{How to cite this article?}

Naik R, Thakur R, Sahare K.K, Lakra A.M, Singh D, Bhagat C.P. Intubating conditions, onset, duration and side effects with rocuronium and atracurium: A comparative study. Int J Med Res Rev 2018; 6 (08): 464-470. doi:10.17511/ijmrr.2018.i08.11. 